\title{
The Shaky Foundations of Millennials' Basic Human Needs
}

\section{Young Perspectives}

\author{
Julia Tréhu ${ }^{1}$
}

Published online: 16 October 2017

(C) Springer Science+Business Media, LLC 2017

A failsafe think-piece begins by caricaturizing the unique pathologies of the Millennial generation. Sharing birthdates within a 15 -year period and being blessed with an agility vis-à-vis technology sorely lacking in their dinosaur babyboomer parents apparently permits broad generalizations about an enormous and enormously diverse generation. ${ }^{1}$ Despite the laziness of such assessments of Millennials, it is nevertheless possible to tease out some interpretations of human needs as shaped by the experiences of contemporary 18 to 35 -year-olds.

At the base of Maslow's pyramid, fundamental food and safety needs are, relatively and historically speaking, largely fulfilled in Western society. Yet Western millennials face unpleasant realities: rising inequality; stagnating incomes; poverty despite full-time work ${ }^{2}$; rising "deaths of despair;"3 the burden of student loans; falling behind their parents' generation in income, employment, and home ownership ${ }^{4}$; the

\footnotetext{
${ }^{1}$ William H. Frey, "Diversity defines the millennial generation," Brookings, 28 June 2016.

${ }^{2}$ Gemma Tetlow, "Wage stagnation drives up number of working poor," Financial Times, 7 December 2016.

${ }^{3}$ Anne Case and Angus Deaton, "Rising morbidity and mortality in midlife among white non-Hispanic Americans in the twenty-first century," PNAS 112, no. 49 (2015), 15,078-15,083.

4 "Five charts show why millennials are worse off than their parents," The Financial Times, 29 August 2017.

${ }^{5}$ Joe Myers, "Millennials will be the first generation to earn less than their parents," World Economic Forum, 19 July 2016.
}

\section{Julia Tréhu}

julia.trehu@sciencespo.fr

1 London School of Economics and Political Science and Sciences Po Paris, Paris, France insecurity of gig-economy work, since contractors are denied opportunities for unionization or other benefits of traditional employment ${ }^{6}$; delayed marriage and childbirth due to economic uncertainty. ${ }^{7}$ All these are compounded by fears that technology will continually render all conceivable jobs obsolete.

What is the point of learning to code (the standard prescription for those displaced by automization) when increasingly sophisticated machines will soon write and update their own code better than any human? John Maynard Keynes predicted that specialization and technology would allow for the fulfilling leisure denied our unfortunate toiling ancestors. ${ }^{8} \mathrm{He}$ would likely be dismayed by the contemporary culture of constant work, in which virtue is measured by number of cups of coffee consumed and precarious side-jobs acquired. ${ }^{9}$ While European countries generally afford citizens a broader safety net than the United States - treating health care, for example, as a right rather than a privilege, which may remove significant worries for long-term life choices - presuming that European millennials, many of whom have lived for almost a decade under the insecurity of austerity politics, as in Greece, might have a rosier outlook about their basic material security than their American counterparts is unrealistic.

\footnotetext{
${ }^{6}$ Jia Tolentino, "The Gig Economy celebrates working yourself to death," The New Yorker, 22 March, 2017.

${ }^{7}$ D'Vera Cohn et al., "Barely Half of U.S. Adults are Married - A Record Low," Pew Research Center, 14 December, 2011.

${ }^{8}$ Larry Elliott, "Economics: Whatever happened to Keynes' 15-h working week," The Guardian, 1 September 2008.

${ }^{9}$ Anna Iovine, "People are outraged over this Fiverr subway advertisement," AOL Finance, 10 March 2017. The ad in question reads: "You eat a coffee for lunch. You follow through on your follow through. Sleep deprivation is your drug of choice. You might be a doer.”
} 
Yet Millennials' experience of liberation in the more personal sense is remarkable. The Internet helps break down the stigmas and barriers of individual self-expression and provides endless romantic options, and Western society is increasingly open towards all types of identity. ${ }^{10}$ The contradiction arises when contrasting this increased individual liberation, presented, especially in popular culture, as self-actualization, with material precariousness and mounting unfreedom due to broader economic forces. Frequently-derided trends among Western millennials can perhaps be explained as responses to a situation in which the pinnacle of Maslow's pyramid seems increasingly attainable while its foundations are hollowed out.

Internet articles and best-seller lists overflow with tips for self-improvement, "hacks" for your body and mind in work, life, and love. Lean In-style corporate feminism focuses largely on how an individual woman should conduct herself to climb the corporate ladder. ${ }^{11}$ Millennials flounder in a sea of buzzwords: wellness, productivity, optimization. Lifestyle brands tailored largely to wealthy, white women sell snakeoil supplements ironically similar to those hawked by rightwing talk-radio conspiracy theorists, proving the allure of the argument that the world is trying to kill you, and that protection can only be assured through purchasing dubious products or via enlightened lifestyle practices, "experts" be damned. ${ }^{12}$ While a certain level of relative privilege or material comfort are necessary to have enough "stuff" to purge in pursuit of the popular "minimalist" aesthetic and lifestyle, this trend can also be explained by the fact that seeking abundance - human nature's drive to accumulate sustenance and possessions to ensure security - now seems impossible, unattainable, or simply in poor taste. Fetishizing minimalism may be a response to previous generations' material gluttony, but also a means of rationalizing the inevitable belt-tightening imposed by material uncertainty.
Commentary on these trends leads to stereotyping millennials as self-absorbed narcissists. But so-called self-indulgent or irrational practices are a response to growing doubts about the capacity to fulfill the basic needs of the pyramid, the manifestations of a frantic attempt to control material existence when its undermining appears imminent. It is impossible to control the abstract economic forces hollowing out the pyramid's foundations, and anyway, There Is No Alternative. But Millennials terrified by professional precariousness can seek control and thus a veneer of self-actualization through strict individual self-optimization, curation of an idealized social media presence, or dubious health fads. When common knowledge holds that the system is rigged and unfair, prioritizing self-improvement is a plausible response.

Yet Millennials are not just rearranging the deck chairs on the Titanic, despite the short-term appeal of a distraction from looming helplessness, but are responding to the destabilized pyramid by imagining political alternatives that will ultimately shape their future more meaningfully than kale-laced juices. From the right, violent online subcultures of identitarian politics, anti-feminism and racial hierarchies herald a dark turn echoed in the zero-sum worldviews of current Western authoritarians. But from the left, frustrated millennials are leapfrogging the neoliberal turn of their parents' generation, finding inspiration in the old-school socialism of Bernie Sanders, Jeremy Corbyn, and Jean-Luc Mélenchon. Whichever vision ultimately prevails, rest assured that the revolution will be Instagrammed.

Julia Tréhu majored in History at Princeton University, graduating in 2014. She is currently pursuing a Dual Degree in International Affairs, studying International Security at Sciences Po Paris and International Political Economy at the London School of Economics.

\footnotetext{
${ }^{10}$ Lucy Clarke-Billings, "What do Tinder's 37 new gender identity options mean?" Newsweek, 18 November 2016.

${ }^{11}$ Ginia Bellafonte, "The False Feminism of 'Fearless Girl,"” The New York Times, 16 March 2017.

${ }_{12}$ Molly Young, "How Amanda Chantal Bacon Perfected the Celebrity

Wellness Business," The New York Times Magazine, 25 May 2017.
} 